\title{
Estelle Barrett
}

Deakin University

\section{What Does it Meme? The Exegesis as Valorisation and Validation of Creative Arts Research}

\begin{abstract}
This paper will draw on Richard Dawkin's idea of the 'meme' to discuss how the creative arts exegesis can operate as valorisation and validation of creative arts research. According to Dawkins, the rate and fecundity of replication permits an artefact to achieve recognition and stability as a meme within a culture. The value and application of traditional forms of research is underpinned by a secondary order of production, publication, that establishes visibility of the work and articulates its empirical processes and findings as sources of social benefit and cultural enhancement.

In the arts, conventional modes of valorisation such as the gallery system, reviews and criticism focus on the artistic product and hence, lack sustained engagement with the creative processes as models of research. Such engagement is necessary to articulate and validate studio practices as modes of enquiry.
\end{abstract}

A crucial question to initiate this engagement is: 'What did the studio process reveal that could not have been revealed by any other mode of enquiry?'

Re-versioning of the studio process and its significant moments through the exegesis locates the work within the broader field of practice and theory. It is also part of the replication process that establishes the creative arts as a stable research discipline, able to withstand peer and wider assessment. The exegesis is a primary means of realising creative arts research as 'meme'.

I would like to suggest that the notion of the 'meme' is a useful one for addressing a number of key questions relating to creative arts research generally, and to the exegesis in particular. These questions are as follows:

* What is it?

* Why do we need it?

* What can it do within the context of a knowledge economy?

* How do we judge its success and value? 
What is to follow is prefaced by an acknowledgment that the field of creative arts is a heterogeneous one, and that not all those who would call themselves artists, may choose to practice or seek recognition within a research framework. However, those who do seek endorsement of their practices by pursuing a higher degree and other forms of practice-based research within the university, are working in a relatively new discipline of research and will thus inevitably be subject to evaluation according to criteria that relate to research and the knowledge economy in general.

Let us start with a brief definition of 'meme' which will be extended as this paper proceeds. In his description of memes, Richard Dawkins (1981) observes that survival of such entities is dependent on the capacity for selfreplication, fitness or the likelihood of being replicated and fecundity or speed of replication to produce critical mass and ensure stability. An evolutionary advancement on their biological counterparts, memes can be described as cultural replicators. Drawing on Dawkin's earlier work, Richard Brodie (1996) describes memes as the basic building blocks of culture; ideas that form themselves into distinct memorable units and which are spread by something as simple as communicating. It should be noted that the cultural artefact - the tune, painting, poem, for example - is not the meme itself, but is a vehicle by which the meme, an idea or internal representation is externalised. Within this context, the exegesis may be viewed both as a replication or re-versioning of the completed artistic work as well as a reflective discourse on significant moments in the process of unfolding and revealing. As 'meme', it can operate both as a noun - an artefact in its own right, and a verb - a re-enactment of the artefact as process. As such it has the potential to reflect and map the logic from which a particular model of representation has emerged. Through this double articulation, the exegesis becomes a vehicle for validating the process of studio enquiry and elaborating the value of its outcomes.

The evolution, stability and successful application of ideas and knowledge derived from research depends on how well such knowledge is replicated and understood by others. However, the replication mechanisms that have traditionally valorised and validated creative arts practices have focussed on product rather than process. Moreover, such mechanisms have tended to rely on the mystification of artistic products as commodities rather than an elucidation of creative arts practices as alternative modes of understanding the world and of revealing new knowledge.

An understanding of the meme as a vehicle for fixing ideas in our collective consciousness allows us to recognise how conventional valorisation of the artefact as product proceeds at the expense of an appreciation of the value of creative processes as modes of revealing - in other words as modes of enquiry and research.

An appraisal of conventional means of valorisation bears this out.

Paradoxically the process that valorises art as commodity is at the same time a process of mystification rather than illumination. The more a work is reproduced in catalogues, books, magazines, on chocolate boxes and T-shirts, and sold and resold in by dealers, the greater is the aura of awe and mystique that surrounds it. This is particularly pertinent to the visual arts as demonstrated in Brian O' Doherty's description of the modernist gallery and its discourses as 'white cube', one which I suggest, continues to have relevance. O' Doherty points out that the conventional gallery with its white walls, sealed windows, polished floors and light emanating from the ceiling can be likened to a church or tomb: 
The ideal gallery subtracts from the artwork all cues that interfere with the fact that it is "art". The work is isolated from everything that would detract from it own evaluation of itself. (O'Doherty, 1976: 14)

The work in this context is given a sense of eternal sameness, a hermetically sealed repository of its maker's divine inspiration. The viewer of the work also relinquishes time and lived experience within the frame of sympathetic magic or mystique that is created. The idea of artist as genius, enhanced through modernist discourse has also added to the auratic nature of art that continues to dominate general perceptions. Indeed many artists themselves subscribe to the mystification process through their reluctance to discuss the origin and situated meanings of completed works. On the other hand artists are also often critical of institutional discourses on art that are removed from the experience of making and the individual consciousness of the maker:

...A painting which has always a certain significance, at least as much as the man who did it. As soon as it is bought and hung on the wall takes on quite a different kind of significance and the painting is done for. (Chipp quotes Picasso, 1968:272)

Picasso's comment relates to the tendency of institutional discourses to be dislocated from the studio process and its experiential, conceptual and intellectual framework. Michel Carter suggest a further disengagement of discourses from the process of inquiry results from the implication of such discourses in market forces through their focus on art works as precious objects. Whilst art historians and critical commentators may present a divergence of views on philosophical value of artistic output, Carter observes: 'intellectual interest can quickly get transformed into economic interest. New meanings are equated to new [monetary] values' (Carter, 1990: 115).

Whatever their intellectual benefits, one could argue that conventional forms of criticism tend to focus on the finished product rather than material, intellectual and cognitive processes that produced it. The meme itself, or the internal representation of ideas that produced the artwork is then obscured by the vehicle in which it is carried. I should like to emphasise that this is not a denial of the intrinsic and generative value of the artworks and their capacity, in some instances, to stand alone as an object of knowledge. However, I do I believe there is a need for a shift in current perceptions of the role and status of the creative arts in the knowledge economy and that the exegesis is a crucial vehicle for effecting this shift.

The exegesis as an illumination and replication of the meme or internal representation can adjust the critical focus and thus has the potential to valorise and validate the mode of inquiry as one worthy of recognition alongside research approaches belonging to more generously supported disciplines in the university and broader cultural arena. To put it another way, the exegesis is a means of articulating a more profound rationale for institutional recognition and support of creative arts research.

In proposing this, I draw on Elliot W. Eisner's view that we need new ways of representing ideas and of illuminating the world and domains of knowledge. Eisner observes that a growing recognition of the limits of traditional ways of representing the world has given rise to a search for alternative approaches to transform and represent the contents of consciousness. Researchers are recognising that scientific inquiry is just one species of research and that 'research is not merely a species of social science' (Eisner, 1997: 261). 
Dissatisfaction with positivism and behaviourism as reductive modes of knowing has also come from within the science disciplines themselves. In his essay, 'The Representation of Nature in Contemporary Physics' (1972), Werner Heisenberg states that the knowledge of science is applicable only to limited realms of experience and the scientific method is but a single method for understanding the world. Moreover, the notion of scientifically-based knowledge as statements of ultimate truth contains an inner contradiction since 'the employment of this procedure changes and transforms its object' (Heisenberg, 1972:189). The work of Heisenberg and others reveals that knowledge is relational and that different models of inquiry will yield different forms of knowledge.

Eisner supports the idea that creative arts-based inquiry has a role to play in extending new frontiers of research. He draws on the work of J. Schwab and others in proposing the centrality of practical and experiential knowledge (Eisner, 1997: 261). Understood through the Greek term phronesis, this form of inquiry requires deliberation and 'wise moral choice', or what I would call the attribution of value based on unfolding action and experience. In this framework one can say that the exegesis illuminates particular knowledge and data derived from interacting with the environment (material and social) and then discusses it in relation to what is already presented in theory and general domains of knowledge. I would like to return to the meme analogy to suggest that the potential for innovation lies in this relational aspect of creative arts practice.

Dawkins tells us that evolution occurs through the differential survival of replicating entities. The implication here, is that evolution occurs through change as an adaptation to the demands of the environment. Brodie comments further:

Evolution requires two things: replication with a certain degree of fidelity, and innovation, and a certain degree of infidelity. (1996:68)

The element of 'infidelity' is a crucial one since it implies a departure from customary ways of thinking and doing things. This helps us to understand why and how creative arts practices change over time. It also highlights an important function of the exegesis. In addition to answering the crucial question -'What did the studio process reveal that could not have been revealed by any other mode of enquiry? - the exegesis provides an opportunity for the creative arts researcher to elucidate why and how processes specific to the arts discipline concerned mutate to generate alternative models of understanding. At the same time, the researcher is also able to elaborate the significance of these models within a research context. Unlike those valorisation or replication processes that focus mainly on the economic and aesthetic value of creative works, the creative arts exegesis as meme, is a differential replication that emphasises processes of enquiry and their potential for innovative application beyond the production of the works themselves.

The importance of this task for creative arts researchers is reflected in observations made by Lauchlan Chipman in his paper, 'What Governments Can't Know : The Knowledge Economy and the Market. Chipman points out that the information age to which we belong is one in which knowledge is rapidly replacing primary and industrial production as the basis for global economy. 'Knowledge is becoming the basic building block underlying wealth' (Chipman quotes Thurow , 2002:10). Chipman suggests that in a knowledge economy, it is necessary for a large number of people to 
comprehend the creative output of others in order for such outputs to be sufficiently taken up for the enhancement of society. Within the context of research, 'output' refers not only to the products of creative arts practices which may be judged by conventional criteria of artistic merit, but also to the experimental and material processes through which such products are externalised.

Elsewhere, I have suggested some possible reasons for the slow recognition and acceptance of the value and validity of creative arts research (Barrett 2002). One of these relates to dominance of instrumental and rationalistic modes of thinking within contemporary society. The social philosopher Pierre Bourdieu, contends that social and institutional systems that make up society or the habitus, operate according to two forms of logic: rational logic and an alternative logic, which may be understood as the logic of practice. Bourdieu explains that rationality achieves privileged status by a process of appropriating and subsuming, into its own logic, knowledge and cultural capital generated through practices that employ the alternative logic of practice. (Bourdieu,1990: 56). The exegesis can counteract this cultural 'forgetting' by tracing and highlighting the logic of specific experiential inquiry. Another issue raised my earlier paper, is related to the lack of a critical mass of discourses that expounds the merits of creative arts research. For the exegesis to achieve success as replicator or meme, there will need to be continued efforts to promote and publish the outcomes of research in as many ways as possible.

To conclude, I propose that an understanding of the creative arts exegesis as 'meme' is a useful way of illuminating what the exegesis is and what it has the potential to do. Its fitness for promoting the stability of a creative arts research discipline and advancing the successful evolution of creative arts research, may be judged both according to criteria of scholarly rigour, as well as its capacity to replicate and elucidate the value of studio enquiry processes and their applications within the in the general field of research.

\section{References}

Barrett, Estelle, 2002 'Studio Enquiry as Valid Research', paper presented at Inaugural Research On Research Conference RMIT University, 14 February. Return to paper. Bourdieu, Pierre, 1990, The Logic of Practice, Polity Press, Oxford. Return to paper. Brodie, Richard, 1996, Virus of the Mind: A New science of The Meme, Integral Press, Seattle. Return to paper.

Carter, Michael, 1990, Framing Art, Southwood Press Marrickville NSW. Return to paper. Chipp, Herschell B., 1968, Theories of Modern Art, University of California Press, Berkley. Return to paper.

Dawkins, Richard, 1981, 'Selfish genes and selfish Memes' in Douglas R. Hofstadter and Daniel C. Dennett (eds.) The Mind's I: Fantasies and Reflections on Self and Soul, Harvester, Sussex, 124-146. Return to paper.

Eisner, Elliot, W., 1993, 'Understanding The Future of Educational Research, Educational Researcher, Vol. 22 No. 7, 5-11. Return to paper.

Eisner, Elliot, W., 1997, 'The New Frontier in Qualitative Research Methodology', Qualitative Inquiry, Sept, 1997v3 n3, 259-266. Return to paper.

Heisenberg, Werner (1972). 'The Representation of Nature in Contemporary Physics' in Sally Sears \& G.W. Lord (ed.), The Discontinuous Universe Basic Books, New York, pp. 123-189. Return to paper. O'Doherty, Brian, 1986, Inside The White Cube, The Lapis Press, San Francisco. Return to paper. 
Estelle Barrett is Senior Lecturer in Visual Theory at Deakin University,

Warrnambool. Her research interests include: affect, subjectivity and art; the influence of non-discursive and preverbal modes of knowing in creative practices. These interests are linked to her current work on creative arts as valid research.

TEXT Special Issue

No 3 April 2004

http://www.griffith.edu.au/school/art/text/

Editors: Julie Fletcher and Allan Mann

General Editors: Nigel Krauth \& Tess Brady

Text@griffith.edu.au 